\title{
Pathogenicity induced by indigenous Beauveria bassiana isolate in different life stages of the cotton leafworm, Spodoptera littoralis (Boisduval) (Lepidoptera: Noctuidae) under laboratory conditions
}

\author{
Yasmin Adel Fergani ${ }^{1 *}$ (i) and Elsayed Abd Elhameed Refaei ${ }^{2}$
}

\begin{abstract}
Background: The invincible effects of the entomopathogenic fungi (EPF) under appropriate circumstances compensate for the flaws of chemical insecticides in the control programs. Beauveria bassiana is one of the most elaborated EPF of pest control all over the world. The potential of using the B. bassiana isolate (Y-F_ITS1) was examined against different larval instars (L2, L3, L4, and L5), pupae, and eggs of the cotton leafworm, Spodoptera littoralis (Boisd.) (Lepidoptera: Noctuidae), using different concentrations under laboratory conditions.

Results: In bioassay, 2nd instar larvae of S. littoralis were significantly the most susceptible stage to B. bassiana isolate at $P \leq 0.05$. It is apparent from the results that the cumulative mortality percentage increased with elapsing time with typical symptoms of infection and sporulation. High efficacies ranging from 85.0 to $99.0 \%$ corrected mortality rates were recorded for 2 nd instar larvae at the spore concentration $\left(1 \times 10^{9}\right.$ spores $\left.\mathrm{ml}^{-1}\right)$. The mortality percentage reached $90.0 \%$ for the 3rd instar larvae treated with the same concentration after 5 days. The least mortality rates results were recorded at the 5 th instar larvae. B. bassiana isolate showed an ovicidal effect to the eggs of S. littoralis that reached $100 \%$ mortality when treated with $1.0 \times 10^{8}$ and $1.0 \times 10^{9}$ spores $\mathrm{ml}^{-1}$, while the concentration $1 \times 10^{7}$ and $1.0 \times 10^{8}$ caused 65.0 and $87.0 \%$, respectively. Reduction of adult emergence reached $(0 \%)$ in case of treatment with the highest concentrations $\left(1 \times 10^{8}\right.$ and $1 \times 10^{9}$ spores $\left.\mathrm{ml}^{-1}\right)$. Morphogenetic abnormalities were also recorded.
\end{abstract}

Conclusion: Results of mortality rates and lethal concentration values resulted from the experiments indicated that the tested Y-F_ITS1 isolate was efficient and can be recommended as a potential biocontrol agent against $\mathrm{S}$. littoralis. Further field evaluations are still needed.

Keywords: Entomopathogenic fungi, Beauveria bassiana, Spodoptera littoralis, Pathogenicity, Local isolate

\footnotetext{
* Correspondence: yasminelfergani@gmail.com

'Plant Protection Research Institute, Cotton Leafworm Department,

Bio-insecticides Production Unit, Agriculture Research Center, Giza, Egypt

Full list of author information is available at the end of the article
}

\section{Springer Open}

(- The Author(s). 2021 Open Access This article is licensed under a Creative Commons Attribution 4.0 International License, which permits use, sharing, adaptation, distribution and reproduction in any medium or format, as long as you give appropriate credit to the original author(s) and the source, provide a link to the Creative Commons licence, and indicate if changes were made. The images or other third party material in this article are included in the article's Creative Commons licence, unless indicated otherwise in a credit line to the material. If material is not included in the article's Creative Commons licence and your intended use is not permitted by statutory regulation or exceeds the permitted use, you will need to obtain permission directly from the copyright holder. To view a copy of this licence, visit http://creativecommons.org/licenses/by/4.0/. 


\section{Background}

The cotton leafworm, Spodoptera littoralis Boisduval (Lepidoptera: Noctuidae), is one of the most economically polyphagous pests recorded to attack a vast range of crops (Abou-Bakar, 1997). Heavy concentrations of insecticide treatments in control programs cause serious economic and environmental problems in addition to leaderless resistance to different active ingredients of insecticides (Zedan and Shoulkamy, 2013). There are urgent demands to find effective and non-hazardous control methods for S. littoralis in Egypt (Hazaa et al. 2019). Mycoinsecticides play a promising role for biological control of insect pests, as alternatives to chemical control, with no toxic residues in the environment nor induction of resistance in their insect hosts (Evans 1999). The spectacular effect of entomopathogenic fungi (EPF), over other ordinary microbial control agents, was registered in attacking all developmental stages of insects including eggs, larvae, and pupal stages (Anand et al. 2008). Moreover, their ability to invade non-feeding stages was due to the specific mechanism of invading the host directly through the cuticle (Nguyen et al. 2007). Beauveria spp. products fulfilled the criteria as microbial agents and represent almost half of the total mycoinsecticides in the world (Faria and Wraight 2007). Y-F_ITS1 isolate isolated from Egyptian fauna using trap insect technique, characterized using internal transcribed spacer (ITS) region, was confirmed as $B$. bassiana (accession no. MK773644.1) (Fergani and Yehia 2020).

The main target of this study was to explore the efficacy of an indigenous $B$. bassiana isolate against different stages of $S$. littoralis under laboratory conditions.

\section{Methods}

\section{Rearing of $S$. littoralis}

A laboratory susceptible strain of the cotton leafworm, $S$. littoralis was obtained as egg masses from the research division of the cotton leafworm, Plant Protection Research Institute (PPRI), Agricultural Research Center (ARC), Giza, Egypt. It was reared on castor bean leaves ever since free from any insecticidal exposure for more than 10 generations under the laboratory conditions $\left(26 \pm 2{ }^{\circ} \mathrm{C}, 65 \pm 10 \%\right.$ relative humidity and 8:16 light to dark photoperiod).

\section{Selection and maintenance of fungal cultures}

The entomopathogenic fungal isolate, B. bassiana $\mathrm{Y}-\mathrm{F}_{-}$ ITS1 (accession no. [MK773644.1]) used in this study, was isolated from a soil sample collected from agricultural fields in Dakahlia Governorate, Egypt, using the greater wax moth, Galleria mellonella L. (Fergani and Yehia, 2020). Fungal spores were cultivated at $25.0 \pm 1.0$ ${ }^{\circ} \mathrm{C}$ on Sabouraud dextrose yeast agar (SDAY) medium for 14 days in darkness. Petri dishes showed good growth and spore production traits were selected. After 15 days, spores were harvested by scraping the Petri dishes off with a sterilized glass slide and collected in vials containing $5 \mathrm{ml}$ of sterilized $0.05 \%$ Tween $20(0.1 \%$, $\mathrm{v} / \mathrm{v})$. The suspensions were filtered and then vortexed for $3 \mathrm{~min}$. by shaking. All spore concentrations were assessed by direct count using a hemocytometer chamber to ensure the accuracy of the prepared concentrations. To estimate the median lethal concentration $\left(\mathrm{LC}_{50}\right)$ and lethal concentration $90 \%\left(\mathrm{LC}_{90}\right)$, a series of dilutions were prepared in sterile distilled water to give the range concentrations of $1 \times 10^{6}, 1 \times 10^{7}, 1 \times 10^{8}$, and $1 \times 10^{9}$ spores $\mathrm{ml}^{-1}$ for each bioassay. Spore suspensions were used in all the bioassay studies that were less than $6 \mathrm{~h}$, prepared and were stored on ice.

\section{Pathogenicity of $B$. bassiana against larval instars (L2:L5) of S. littoralis}

Larval instars of S. littoralis (L2-L5) were used in the present experiment. For treatment experiments and control, 30 larvae per replicate were placed in clean glass Petri dishes. Castor leaves were provided to each Petri dish for nutrition. For each tested concentration, 30 larvae were placed on a folded Whatman No. 1 filter paper in a glass funnel, and then $20 \mathrm{ml}$ of the spore suspensions were poured. Sterile distilled water with $0.1 \%$ Tween 20 was used for the control treatment. Treated larvae were left to move freely for 1 min to dry and then transferred to the Petri dishes lined with filter paper to remove excess humidity. All treatments and control were incubated at $25{ }^{\circ} \mathrm{C}$. The whole experiment was repeated 3 times. Mortality rates at each treatment were recorded daily until the 5th day post-treatment. Dead larvae were kept separately in Petri dishes lined with sterilized moistened filter paper and fungal growth was recorded daily for mycosis test to confirm mortality due to infection by the tested isolate.

\section{Effect of B. bassiana on adult emergence of S. littoralis}

Twenty newly formed pupae were transferred gently into a 25-ml glass beaker for each concentration. Ten milliliters of either fungal spore suspension or $0.1 \%$ Tween 20 for control was decanted into the beaker, the immersed pupae were shacked gently for $10 \mathrm{~s}$; then, the suspension was poured and the pupae were transferred to clean plastic pots. All pots were lined with moistened filter paper to maintain high humidity for $24 \mathrm{~h}$. After $24 \mathrm{~h}$, the moistened filter paper was removed. Three replicates were used for each concentration. The percentage of adult emergence was observed and recorded based on the number of pupae that did not develop successfully into viable adults. The emerged adults were also monitored for fungal growth and morphological changes. 
Bio-efficacy of B. bassiana against S. littoralis eggs

The concentration-effect of different dilutions of spore suspensions on eggs was assessed. Autoclaved Petri dishes, for each concentration, were used for egg treatment. Each Petri dish was packed with a layer of cotton at the bottom covered with a layer of tissue paper. Two milliliters of sterile distilled water was added to each Petri dish for humidity. One egg patch for each treatment was surface sterilized by $0.5 \%(\mathrm{v} / \mathrm{v})$ aqueous solution of sodium hypochlorite followed by washing with sterile distilled water. Egg patches were left to dry and then immersed in $2 \mathrm{ml}$ of each tested spore suspension with gentle shaking for $2 \mathrm{~min}$. Excess water was removed, using a sterilized filter paper and the egg patches were transferred to the previously prepared Petri dishes. Average number of eggs in each batch was 250 eggs. Each treatment was replicated 3 times and each egg batch was considered one replicate. The control groups were treated with sterile distilled water containing Tween $20(0.1 \%, v / v)$. The treated and control group were incubated at $25{ }^{\circ} \mathrm{C}$ and were examined daily for 7 days. The color changes in eggs were observed daily. Egg hatchability was recorded and the unhatched eggs were considered dead.

\section{Statistical analysis}

S. littoralis eggs and larval mortality rates caused by the tested EPF isolate was corrected according to Abbott's formula (Abbott 1925). $\mathrm{LC}_{50}$ and $\mathrm{LC}_{90}$ values were estimated according to Finney (1971) using "LdPLine" software [http://embakr.tripod.com/ldpline/ldpline.htm]. Means were analyzed by one-way analysis of variance (ANOVA). Tukey's method of multiple comparison was done using the statistical program Minitab 16.0 at $P \leq$ 0.05 significance level (Minitab Ltd., Coventry, UK). The reduction of adult emergence was calculated according to Khazanie (1979). Reduction \% $=(C-T / C) \times 100$, where $C=$ number of emerged adults in control and $T=$ number of emerged adults after treatment.

\section{Results}

\section{Pathogenicity of $B$. bassiana to $S$. littoralis larval instars}

The pathogenicity of the tested fungal isolate (Y-F_ITS1) serial concentrations (viz. $1.0 \times 10^{6}, 1 \times 10^{7}, 1 \times 10^{8}$, and $1 \times 10^{9}$ spores $\mathrm{ml}^{-1}$ ) on different larval instars was assessed. As shown in Table 1, all the treated larval instars exhibited considerable linear mortality percentages when inoculated with serial concentrations of the fungal isolate (Y-F_ITS1). Beginning from the 1st day posttreatment, the mortality rate of the 2nd instar larvae of S. littoralis recorded 16.0, 23.0, and $30 \%$ at concentrations $1 \times 10^{7}, 1 \times 10^{8}$, and $1 \times 10^{9}$ spores $\mathrm{ml}^{-1}$, respectively. While after 5 days, the least concentration $1 \times 10^{6}$ spores $\mathrm{ml}^{-1}$ caused more than $85 \%$ mortality, while the
Table 1 Efficacy of the Beauveria bassiana (Y-F_ITS1) against different larval instars of Spodoptera littoralis under laboratory conditions

\begin{tabular}{|c|c|c|c|c|c|c|}
\hline \multirow{2}{*}{$\begin{array}{l}\text { Concentrations } \\
\left(\text { spores } \mathrm{ml}^{-1} \text { ) }\right.\end{array}$} & \multirow{2}{*}{$\begin{array}{l}\text { Larval } \\
\text { instars }\end{array}$} & \multicolumn{5}{|c|}{ Mortality percentage } \\
\hline & & 1 day & 2 days & 3 days & 4 days & 5 days \\
\hline \multirow[t]{4}{*}{$1 \times 10^{6}$} & L2 & 0.0 & $16.0^{a}$ & $50.0^{\mathrm{a}}$ & $76.0^{\mathrm{a}}$ & $85.0^{a}$ \\
\hline & L3 & 0.0 & $6.0^{\mathrm{b}}$ & $45.0^{\mathrm{b}}$ & $63.0^{\mathrm{b}}$ & $65.0^{\mathrm{b}}$ \\
\hline & Ł4 & 0.0 & $6.0^{\mathrm{b}}$ & $40.0^{c}$ & $55.0^{c}$ & $63.0^{\mathrm{b}}$ \\
\hline & L5 & 0.0 & $0.0^{c}$ & $10.0^{\mathrm{d}}$ & $13.0^{d}$ & $15.0^{c}$ \\
\hline \multirow[t]{4}{*}{$1 \times 10^{7}$} & L2 & 16.0 & $53.0^{\mathrm{a}}$ & $60.0^{\mathrm{a}}$ & $93.0^{\mathrm{a}}$ & $95.0^{\mathrm{a}}$ \\
\hline & L3 & 0.0 & $33.0^{b}$ & $53.0^{\mathrm{b}}$ & $75.0^{\mathrm{b}}$ & $75.0^{\mathrm{b}}$ \\
\hline & L4 & 0.0 & $16.0^{c}$ & $50.0^{\mathrm{b}}$ & $63.0^{c}$ & $73.0^{b}$ \\
\hline & L5 & 0.0 & $3.0^{d}$ & $13.0^{c}$ & $18.0^{\mathrm{d}}$ & $23.0^{c}$ \\
\hline \multirow[t]{4}{*}{$1 \times 10^{8}$} & L2 & 23.0 & $65.0^{\mathrm{a}}$ & $83.0^{\mathrm{a}}$ & $96.0^{\mathrm{a}}$ & $96.0^{\mathrm{a}}$ \\
\hline & L3 & 0.0 & $38.0^{\mathrm{b}}$ & $80.0^{\mathrm{a}}$ & $86.0^{\mathrm{b}}$ & $88.0^{b}$ \\
\hline & $\llcorner 4$ & 0.0 & $20.0^{c}$ & $53.0^{\mathrm{b}}$ & $73.0^{c}$ & $75.0^{c}$ \\
\hline & L5 & 0.0 & $5.0^{d}$ & $22.0^{c}$ & $25.0^{d}$ & $46.0^{d}$ \\
\hline \multirow[t]{4}{*}{$1 \times 10^{9}$} & L2 & 30.0 & $75.0^{\mathrm{a}}$ & $90.0^{\mathrm{a}}$ & $97.0^{\mathrm{a}}$ & $99.0^{\mathrm{a}}$ \\
\hline & L3 & 0.0 & $43.0^{\mathrm{b}}$ & $85.0^{\mathrm{b}}$ & $89.0^{b}$ & $90.0^{b}$ \\
\hline & $\llcorner 4$ & 0.0 & $23.0^{c}$ & $60.0^{c}$ & $85.0^{c}$ & $88.0^{c}$ \\
\hline & L5 & 0.0 & $7.0^{d}$ & $33.0^{\mathrm{d}}$ & $40.0^{d}$ & $56.0^{d}$ \\
\hline Control & L2:5 & 0.0 & 0.0 & 0.0 & 0.0 & 0.0 \\
\hline
\end{tabular}

Means of the same column at the same concentration followed by different letters are significantly different $(P \leq 0.05)$

highest concentration $1 \times 10^{9}$ spores $\mathrm{ml}^{-1}$ recorded 99\% mortality. Mostly, the death of the 3rd and 4th larval instars started $48 \mathrm{~h}$ post-treatment. At the least concentrations $1 \times 10^{6}$ spores $\mathrm{ml}^{-1}$, the 3rd instar larval mortalities ranged from 6.0 to $65.0 \%$ and the 4 th instar larval percentage mortalities ranged from 6.0 to $63.0 \%$. The highest concentrations $1 \times 10^{9}$ spores $\mathrm{ml}^{-1}$ caused percentage mortalities ranged from 43.0 to $90.0 \%$ for the 3rd instar larvae and 23.0 to $88.0 \%$ for the 4th instar larvae. The minimum percentage mortality was recorded at the 5th instar larvae that started from the 3rd day using the least concentration and reached (15\%) after 5 days post-treatment. Only the maximum concentration showed larval mortality after the 2nd day (7.0\%) and reached $(56.0 \%) 5$ days post-treatment. Obtained results reported that the larval mortality increased by increasing the concentration of the tested $B$. bassiana isolate against no larval mortality in the control. Based on the $\mathrm{LC}_{50}, \mathrm{LC}_{90}$, and non-overlapping fiducially limits calculated on the 5th day post-treatment (Table 2), the tested fungal isolate (Y-F_ITS1) was significantly more virulent to the 2nd instar larvae within the first 2 days after treatment $(P \leq 0.05) . \mathrm{LC}_{50}$ and $\mathrm{LC}_{90}$ values were $2.5 \times 10^{5}$ and $3.0 \times 10^{8}$ spores $\mathrm{ml}^{-1}$, respectively (slope 0.4173). Both L3 and L4 instars showed significantly high mortality levels 3 days post-treatment. Typical symptoms of 
Table 2 Probit analysis of mortality rates of Spodoptera littoralis larval instars (L2:L5) on the 5th day post-Beauveria bassiana (YF_ITS1) treatments

\begin{tabular}{llllll}
\hline Larval instars & $L C$ & Spores $/ \mathrm{ml}$ & Lower limit & Upper limit & Slope \\
\hline$L 2$ & $L C_{50}$ & $2.5 \times 10^{5}$ & $4.7 \times 10^{3}$ & $4.5 \times 10^{6}$ & 0.4173 \\
& $L C_{90}$ & $3.0 \times 10^{8}$ & $5.1 \times 10^{7}$ & $9.5 \times 10^{8}$ & \\
L3 & $L C_{50}$ & $6.2 \times 10^{7}$ & $1.0 \times 10^{7}$ & $3.9 \times 10^{9}$ & 0.3247 \\
& $L C_{90}$ & $5.5 \times 10^{11}$ & $1.4 \times 10^{11}$ & $8.5 \times 10^{12}$ & \\
$L 4$ & $L C_{50}$ & $1.7 \times 10^{8}$ & $1.0 \times 10^{5}$ & $2.9 \times 10^{9}$ & 0.1986 \\
& $L C_{90}$ & $5.0 \times 10^{10}$ & $3.3 \times 10^{12}$ & $7.0 \times 10^{12}$ & \\
$L 5$ & $L C_{50}$ & $1.5 \times 10^{13}$ & $4.7 \times 10^{9}$ & $8.4 \times 10^{13}$ & 0.2955 \\
& $L C_{90}$ & $3.2 \times 10^{13}$ & $1.4 . \times 10^{11}$ & $9.0 \times 10^{16}$ & \\
\hline
\end{tabular}

white muscardine infection were observed on the dead larvae that were kept under humid conditions. It could be concluded that the 2nd instar larvae of $S$. littoralis were significantly more susceptible to the tested fungal isolate (Y-F_ITS1) than the others $(P \leq 0.05)$ and the mortality rates was correlated to increasing the fungal concentrations.

\section{Bio-efficacy of $B$. bassiana against S. littoralis eggs}

Results of the bioassay proved that the eggs of S. littoralis were highly susceptible to the tested fungal isolate (YF_ITS1) (Fig. 1) resulting in 100\% egg mortality in case of treatment with $1 \times 10^{8}$ and $1 \times 10^{9}$ spores $\mathrm{ml}^{-1}$, while the treatment with $1 \times 107$ spores $\mathrm{ml}^{-1}$ caused the mortality rates equal to $87.0 \%$. The minimum mortality rates $65.0 \%$ were observed in case of the treatment with $1 \times$ $10^{6}$ spores $\mathrm{ml}^{-1}$, while it was no egg mortality in the control. It was also noticed that the eggs succeeded to hatch showed $100 \%$ death of neonate individuals just after $24 \mathrm{~h}$ (Fig. 1). The egg hatching period in treated patches did not exceed 2 days; $\mathrm{LT}_{50}$ value was not calculated.
Effect of $B$. bassiana isolate against pupae of $S$. littoralis The pupae of $S$. littoralis were highly susceptible to $B$. bassiana isolate using immersion method that caused the maximum reduction $(0 \%)$ in adult emergence in case of treatment with the highest concentrations $\left(1 \times 10^{8}\right.$ and $1 \times 10^{9}$ spores $\mathrm{ml}^{-1}$ ), followed by $87.0 \%$ adult emergence in case of treatment at $1 \times 10^{7}$ spores $\mathrm{ml}^{-1}$. The minimum adult emergence $(65.0 \%)$ was recorded at $1 \times$ $10^{6}$ spores $\mathrm{ml}^{-1}$. Maximum adult's emergence in the control was observed. Also, after treatment with the low concentrations, a delay of adults' emergence and some malformation characteristics as compared to the controls was noticed (Fig. 2).

\section{Discussion}

In the present study, the tested B. bassiana isolate (Y-F_ ITS1) showed pathogenic effect towards different life stages of $S$. littoralis with increasing mortality in a concentration-dependent manner. The 2nd instar larvae were significantly more susceptible than the other instars (at $P \leq 0.05$ ). These results agreed with that of the previous studies of El-Katatny (2010) on the impact of $B$. bassiana on S. littoralis. The ovicidal effects of the tested fungal isolate were also observed towards the egg stage of S. littoralis that reached $100 \%$ at the highest concentrations and with $100 \%$ mortality of neonate individuals just after $24 \mathrm{~h}$. A similar ovicidal effect of $B$. bassiana against $S$. litura (Fabricius) (Lepidoptera: Noctuidae) was recorded by Anand and Tiwary (2009) who clarified that the humid medium up to $90 \%$ might be the main reason for the ovicidal activity of B. bassiana. Also, the ovicidal activity of B. bassiana isolates to beet armyworm, Spodoptera exigua (Hübner) (Lepidoptera: Noctuidae), was proved by Al-Kherb (2014), causing 50\% mortality, using spore concentration equal to $1 \times 10^{5}$ spores $/ \mathrm{ml}$, where $B$. bassiana showed superiority over $M$. anisopliae in controlling the eggs. The egg hatching was significantly lowered in S. littoralis upon infection with other fungal isolates as Penicillium falicum, A. terreus, A. parasiticus,

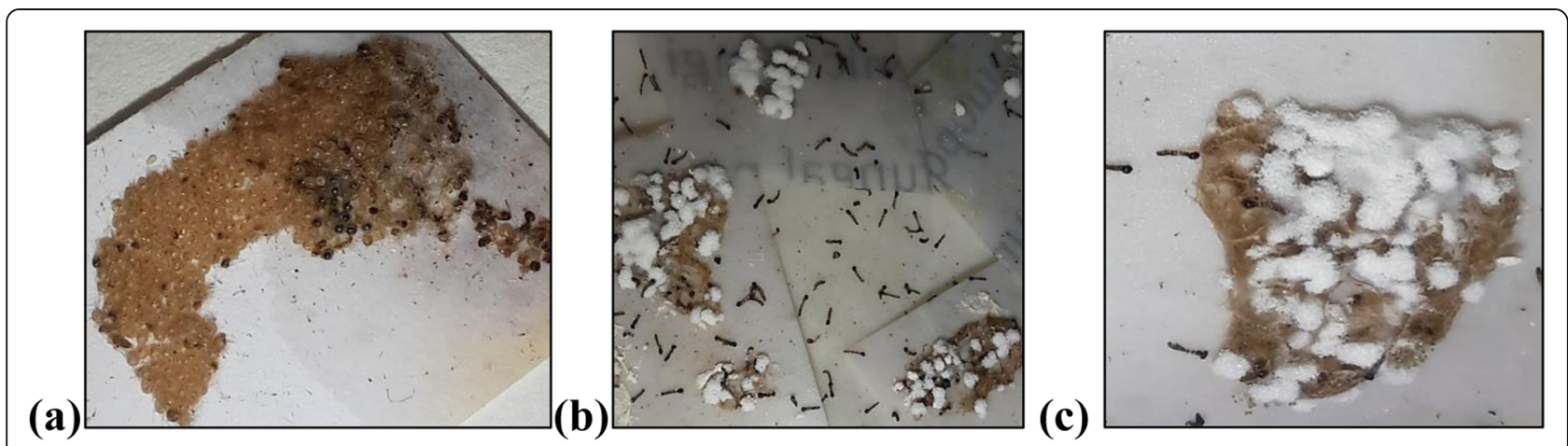

Fig. 1 Eggs of Spodoptera littoralis after treatment with Beauveria bassiana spore suspensions using immersion method covered with white mycelium. a Normal egg patch. b, c Egg patches covered with the white mycelium and dead neonate after $24 \mathrm{~h}$ of emergence 
(a)

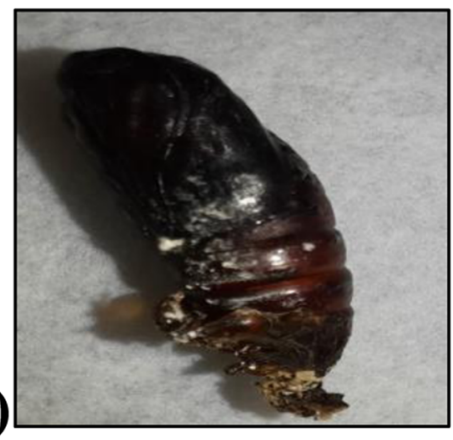

(b)

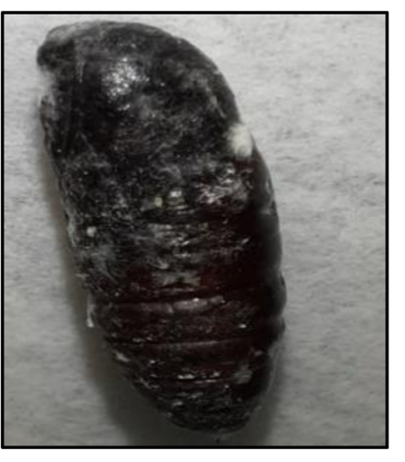

(c)

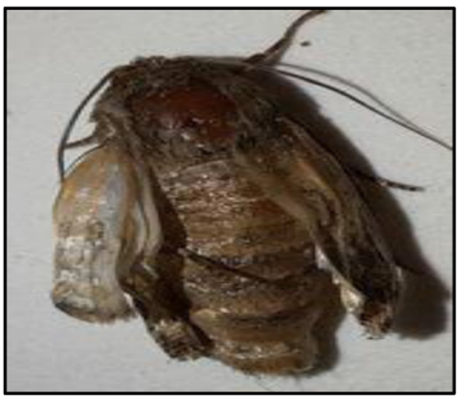

(d)

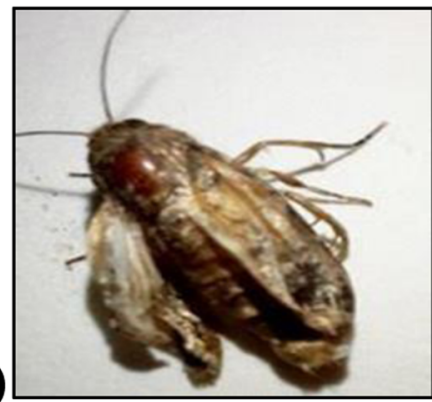

(e)

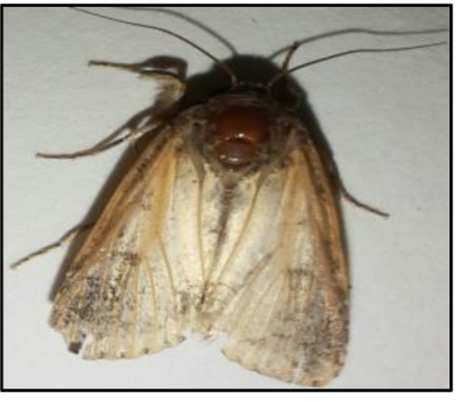

Fig. 2 Pupae of Spodoptera littoralis after the treatment with Beauveria bassiana spore suspensions using immersion method covered with white mycelium (a, b), deformed adult after emergence and $\mathbf{c}, \mathbf{d}$ deformed and e normal adult

and A. flavus within 5 days post-treatment (Zedan and Shoulkamy, 2013). Many authors have proposed that the egg stage is the most resistant stage to fungal infections (Gopalakrishanan and Narrayanan 1989; Mochi et al. 2009). High reduction rates were recorded after treatment of pupae with high concentrations of the tested fungal isolate (Y-F_ITS1). These results were in line with Nguyen et al. (2007) who found that B. bassiana also showed a high reduction in adult emergence from pupae of Helicoverpa armigera using the soil inoculation method and the pupal immersion technique. On the other hand, Ullah et al. (2019) found that B. bassiana had insignificant effect on the adult emergence rate of $S$. litura. Also, Asi et al. (2013) expressed the highly resistant behavior of pupae toward fungal infection than other developmental stages of S. litura. De La Rosa et al. (2002) suggested the resistance of pupae to fungal infection due to the effective sclerotized cuticle that offers protection to insect pupae. The other assumption postulated that the virulence of EPF towards pupae might be due to the pattern of cuticle degrading enzymes such as chitinases, protease, and lipase Dhawan and Joshi (2017) which enable fungi to overcome the innate immunity of the insect when the fungus comes into contact with hemolymph (Wang and Leger, 2006). The delayed emergence and malformed characters that appeared during treatment with low concentrations were also recorded. The malformed adult was short in length with crumbled wing lobes, antenna, and abdomen reduced highly in length. This was in line with Sakr (2007) who observed abnormal changes in emerged adults as fang-mask mouthparts and crippled adults wings of S. littoralis treated with Streptomyces lavendulae (Streptomycetaceae). The malformations made adults unable to have neither normal flight behavior nor mating and this was in agreement with Asi et al. (2013). B. bassiana isolate could be applied directly in the soil where the fully grown larvae of $S$. littoralis pushes the loose surface of the soil downwards forming a cocoon in which it usually pupates within 5-6 h (Pinhey, 1975) to diminish the emergence of the adult or reduce the ability of them to complete normal life cycle. Also, due to the cryptic habit (larvae feed on leaves and pupate in soil), and a high rate of infestation post heavy rains (Garrido-Jurado et al. 2020). B. bassiana-based mycoinsecticide have distinct advantages over other microbial control agents in soil treatment of S. littoralis during pupation period. It is clear from the mentioned results that the comparison between total mortality percentages recorded at the 4 different concentrations $\left(10^{6}, 10^{7}, 10^{8}\right.$, and $10^{9}$ spore $\mathrm{ml}^{-1}$ ), spore suspension of $B$. bassiana isolate towards eggs, and different larval instars and pupae indicated that the spore suspension concentration of $10^{9}$ spore $\mathrm{ml}^{-1}$ gave the best pathogenic effects.

Entomopathogenic fungi belonging to Hyphomycetes such as B. bassiana were recommended to control a 
wide range of insect pests and could play an important role in the regulation of pest populations (Smith et al. 1999). Numerous studies have demonstrated the pathogenic effect of $B$. bassiana against $S$. littoralis, in a recent paper, Fergani and Yehia (2020) highlighted the high susceptibility of G. mellonella to the tested isolate of $B$. bassiana (Y-F_ITS1). The considerable pathogenic effect induced by this indigenous $B$. bassiana isolate towards the different life stages of $S$. littoralis proved to be effective with sufficient concentrations and it recommended being included as a part of the biological control systems of IPM programs against $S$. littoralis. Hence, further studies are needed to meet the demands of finding effective, non-polluted, and safe $B$. bassiana-based mycoinsecticides used on large-scale applications against economic pests in Egypt.

\section{Conclusion}

Based on the results, it could be concluded that the tested fungal isolate (Y-F_ITS1) with high concentrations as $1 \times 10^{8}$ and $1 \times 10^{9}$ spores $\mathrm{ml}^{-1}$ was a potent $B$. bassiana isolate that caused high mortality percentage and morphogenetic abnormalities. Also, it was concluded that the tested fungal isolate could be developed and recommended as mycoinsecticides with a special formulation to control the cotton leafworm, S. littoralis, as part of IPM programs under appropriate circumstances.

\footnotetext{
Abbreviations

IPM: Integrated pest management; EPF: Entomopathogenic fungi; $B$. bassiana: Beauveria bassiana; S. littoralis: Spodoptera littoralis; ITS: Internal transcribed spacer; G. mellonella: Galleria mellonella; SDAY: Sabouraud dextrose yeast agar; $L_{50}$ : Median lethal concentration; LC 90 : Lethal concentration 90\%; M. anisopliae: Metarhizium anisopliae; S. litura: Spodoptera litura; A. terreus: Aspergillus terreus; A. parasiticus: Aspergillus parasiticus; A. flavus: Aspergillus flavus
}

\section{Acknowledgements}

The authors wish to express their most sincere gratitude to Dr. Heba Mohamed Hamama (Entomology Department, Faculty of Science, Cairo University) for critical revising of the manuscript.

\section{Authors' contributions \\ All authors contributed significantly to this research and the preparation of the manuscript. YF and RS carried out the experiments. YF analyzed the data; YF and RS were involved in the conception and design of the study. YF, methodology, writing, and editing. All authors read and approved the final manuscript.}

\section{Funding}

Any funding from any organization did not support this work.

\section{Availability of data and materials}

The datasets used and/or analyzed during the current study are available from the corresponding author on reasonable request.

\section{Declarations}

Ethics approval and consent to participate

Not applicable.

\section{Consent for publication}

Not applicable.

\section{Competing interests}

The authors declare that they have no competing interests.

\section{Author details}

${ }^{1}$ Plant Protection Research Institute, Cotton Leafworm Department, Bio-insecticides Production Unit, Agriculture Research Center, Giza, Egypt. ${ }^{2}$ Plant Protection Research Institute, Biological Control Department, Agriculture Research Center, Giza, Egypt.

Received: 30 December 2020 Accepted: 6 April 2021

Published online: 16 April 2021

\section{References}

Abbott WS (1925) A method of computing the effectiveness of an insecticide. J Econ Entomol 18:265-267. https://doi.org/10.1093/jee/18.2.265a, 2

Abou-Bakar H (1997) Metahrizium anisopliae (Metsch.) Sorokin, a potential entomogenous fungus for controlling cotton leafworm, Spodoptera littoralis (Boisd.) in clover fields. Egypt J Biol Control 7(1-2):111-114

Al-Kherb WA (2014) Virulence bio-assay efficiency of Beauveria bassiana and Metarhizium anisopliae for the biological control of Spodoptera exigua (Hübner) (Lepidoptera: Noctuidae) eggs and the $1^{\text {st }}$ instars larvae. Aust J Basic Appl Sci 8(3):313-323

Anand R, Prasad B, Tiwary BN (2008) Relative susceptibility of Spodoptera litura pupae to elected entomopathogenic fungi. Biocontrol 54(1):85-92

Anand R, Tiwary BN (2009) Pathogenicity of entomopathogenic fungi to eggs and larvae of Spodoptera litura, the common cutworm. Biocontrol Sci Technol 19(9):919-929. https://doi.org/10.1080/095831509032

De La Rosa W, Lopez FL, Liedo P (2002) Beauveria bassiana as a pathogen of the Mexican fruit fly (Diptera: Tephritidae) under laboratory conditions. J Econ Entomol 95(1):36-43. https://doi.org/10.1603/0022-0493-95.1.36

Dhawan M, Joshi N (2017) Enzymatic comparison and mortality of Beauveria bassiana against cabbage caterpillar Pieris brassicae LINN. Brazil J Microbiol 48(3):522-529. https://doi.org/10.1016/j.bjm.2016.08.004

El-Katatny MH (2010) Virulence potential of some fungal isolates and their control-promise against the Egyptian cotton leafworm, Spodoptera littoralis. Arch Phytopathol Plant Protec 43(4):332-356. https://doi.org/10.1080/032354 00701806278

Evans HC (1999) Biological control of weed and insect pests using fungal pathogens, with particular reference to Biocon. News Inform 20(2):63

Faria MR, Wraight SP (2007) Mycoinsecticides and mycoacaricides: a comprehensive list with worldwide coverage and international classification of formulation types. Biol Control 43(3):237-256. https://doi.org/10.1016/j. biocontrol.2007.08.001

Fergani YA, Yehia RS (2020) Isolation, molecular characterization of indigenous Beauveria bassiana isolate, using ITS-5.8 s rDNA region and its efficacy against the greatest wax moth, Galleria mellonella L. (Lepidoptera: Pyralidae) as a model insect. Egypt J Biol Pest Control 30:96. https://doi.org/10.1186/s41938020-00298- $x, 1$

Finney DJ (1971) Probit analysis, 3rd edn. Cambridge University Press, Cambridge, p 333. https://doi.org/10.1002/jps.2600600940, 60, 9, 1432.

Garrido-Jurado I, Resquín-Romero G, Yousef-Naef M, Ríos-Moreno A, QuesadaMoraga E (2020) Soil drenching with entomopathogenic fungi for control of the soil-dwelling life stages and adults of the same generation of Spodoptera littoralis (Boisd.) (Lepidoptera: Noctuidae). Bull Entomol Res 110(2):242-248. https://doi.org/10.1017/S000748531900052X

Gopalakrishanan C, Narrayanan K (1989) Studies on the susceptibility of Heliothis armigera Hubner (Lepidoptera: Noctuidae) to the entomopathogenic fungus Metarhizium anisopliae var anisopliae. Tulloch Entomon 14(3-4):191-198

Hazaa MAM, Mohsen El, Alm El-din MMS, Hassan RS, Ashoush SRM (2019) Biocontrol potential of some entomopathogenic fungi against the cotton leafworm Spodoptera littoralis in vitro. Nucl Tech Appl Sci 7(65):78. https://doi. org/10.21608/jntas.2019.54554

Khazanie R (1979) Elementary statistics. Good Year Publishing Co., California, USA, p 488PP

Mochi DA, Monteiro AC, Machadoa ACR, Yoshida L (2009) Efficiency of entomopathogenic fungi in the control of eggs and larvae of the horn fly Haematobia irritans (Diptera: Muscidae). Vet Parasitol 167(1):62-66. https:// doi.org/10.1016/j.vetpar.2009.09.046

Nguyen NC, Borgemeister HP, Zimmermannn G (2007) Laboratory investigations on the potential of entomopathogenic fungi for biocontrol of Helicoverpa 
armigera (Lepidoptera: Noctuidae) larvae and pupae. Biocon Sci Tec 17(12): 853-864. https://doi.org/10.1080/09583150701546375

Pinhey ECG (1975) Moth of Southern Africa, description and colour illustrations of 1183 species. A. A. Balkema. Rotterdam, The Netherlands. (7+)273pp.

Sakr HH (2007) Toxicity of Streptomyces lavendulae (Streptomycetaceae) culture filtrate to Spodoptera littoralis (Boisd.) larvae (Lepidoptera: Noctuidae). Egypt J Exp Biol (Zool) 3:197-202

Smith SM, Moore D, Karanja LW, Chandi EA (1999) Formulation of vegetable fat pellets with pheromone and Beauveria bassiana to control the larger grain borer, Prostephanus truncates (Horn). Pest Sci 55:711-718. https://doi.org/10.1 002/1096-9063, 7

Ullah MI , Altaf N, Afzal M, Arshad M, Mehmood N, Riaz M (2019) Effects of entomopathogenic fungi on the biology of Spodoptera litura (Lepidoptera: Noctuidae) and its Reduviid predator, Rhynocoris marginatus (Heteroptera: Reduviidae). Int J Insect Sci 11:1-7. https://doi.org/10.1177/117954331986711

Wang C, Leger S (2006) A collagenous protective coat enables Metarhizium anisopliae to evade insect immune responses. Proc Natl Acad Sci USA 103: 6647-6652. https://doi.org/10.1073/pnas.0601951103, 17

Zedan SA, Shoulkamy MA (2013) Use of entomopathogenic fungi for control of the Egyptian cotton leafworm, Spodoptera littoralis. J Nutr Food Sci 3:4. https://doi.org/10.4172/2155-9600.S1.010, 01

\section{Publisher's Note}

Springer Nature remains neutral with regard to jurisdictional claims in published maps and institutional affiliations.

\section{Submit your manuscript to a SpringerOpen ${ }^{\circ}$ journal and benefit from:}

- Convenient online submission

- Rigorous peer review

- Open access: articles freely available online

High visibility within the field

- Retaining the copyright to your article

Submit your next manuscript at $\boldsymbol{\nabla}$ springeropen.com 